\title{
A Qualitative Analysis on the Clinical Experiences of Undergraduate Nursing Students in Kenya
}

\author{
Wachira Serah $^{1 *}$, Karani Anna ${ }^{2}$, Kimani Samuel ${ }^{2,}$ Mageto Irene $^{2}$ \\ ${ }^{1}$ Department of Nursing Daystar University, Nairobi \\ ${ }^{2}$ Department of Nursing University of Nairobi
}

DOI: $10.36348 /$ sjnhc.2020.v03i11.003

| Received: 21.10.2020 | Accepted: 05.11.2020 | Published: 09.11.2020

*Corresponding author: Wachira Serah

\section{Abstract}

Background/aim: There is a need to assess students' reflective work to identify learning enhancers and barriers to improve nurse training. Although reflective writing has been an ongoing clinical nurse education practice globally, analysis of journal reflections to identify student nurses' clinical experiences is scanty, especially in the local Kenyan setting. Therefore, the purpose of this study was to evaluate the lived clinical experiences of student nurses to identify learning enhancers and barriers. Methods: This research was the qualitative part of a mixed-method approach. Qualitative content analysis was utilized to scrutinize 138 reflective journal entries of 36 undergraduate nursing students in the second and third years of practice. The participants were from a Public University, School of Nursing, in Kenya. The students documented their clinical experiences during their medical-surgical clinical attachment at a National Referral Hospital in Kenya between February and August 2018. The average entries per student were four with a range of 2-6 entries per journal. Gibb's reflective model guided documentation of reflections. NVIVO version 11 was used to code, transcribe, and analyze the journal narratives. Results: Four main themes emerged from the analysis; Gaining new skills and knowledge, confidence levels, professional practice gaps, and professional support system. Conclusion: Nursing students' experience is focused on gaining new knowledge and skills and building their confidence to practice. However, positive and negative encounters develop their buoyancy and frustrate their desire to learn, respectively.

Keywords: Clinical Experiences, Reflective Journaling, Nursing, Students.

Copyright (C) 2020 The Author(s): This is an open-access article distributed under the terms of the Creative Commons Attribution 4.0 International License (CC BY-NC 4.0) which permits unrestricted use, distribution, and reproduction in any medium for non-commercial use provided the original author and source are credited.

\section{INTRODUCTION}

The amalgamation of theory and clinical practice is vital in training student nurses to provide quality, safe patient care as professionals. Students quickly transfer knowledge to practical situations when interacting with real-life experiences in the clinical setting [1]. A clinical learning environment that is supportive, resourceful, and individualized ensure that student nurses fit in the health care team and are comfortable learning from their mistakes [2].

This study utilized reflective journaling as a student-directed learning strategy to help them reflect on their clinical experiences. Reflection helps students identify gaps in their learning [3]. It supports the development of profound knowledge, critical thinking skills, and confidence [4]. Reflections can act as opportunities for voicing painful experiences encountered during clinical practice [5]. Analysis of such observations helps improve the clinical learning environment for better outcome of training. Use of documented reflections can enhance student experiences to strengthen their incorporation into the profession [6].

There is a need to assess students' reflective work to identify learning enhancers and barriers that can help improve nurse training. Although reflective writing has been an ongoing clinical nurse education practice globally, analysis of journal reflections to identify student nurses' clinical experiences is scanty, especially in the local Kenyan setting. Most studies have focused on assessing the level of reflection $[4,7]$; or improving thoughtful writing $[8,3]$. The few studies that have analyzed student reflections found that most students were concerned about whether they acted professionally in communicating with the patient and performing nursing skills [9]. Another study identified feedback, taking responsibility, and the opportunity to practice as factors that promoted students' clinical learning. Hindering factors included inconsistent supervision and feelings of personal inadequacies [10] 
Multiple studies in this area used questionnaires, interviews, and observational data collection methods rather than analysis of reflections. A study done to evaluate student nurses' clinical learning experiences through observation and interviews found that the participants had the opportunity to gain new skills, but felt intimidated by the qualified nursing staff's negative attitude towards them. This experience affected their confidence in attempting new procedures [11]. Warne et al. [12] studied the enhancers of clinical skills for nursing students from nine European countries. Their study concluded that the students had a pleasant experience with a supportive mentoring system. Similar studies have found a correlation between student- preceptor relationship and clinical experience. Lawal et al., [13], for instance, identified that when students' relationships with the preceptor were enhanced, the clinical experience was pleasant [14]. Recognized various challenges of clinical teaching in a Malawian hospital environment. Their study reported that most students identified resource constraint as a significant hindrance to their learning.

There has been minimal use of reflective journaling in Nursing Education in Kenya despite the benefits cited globally. This study aimed at identifying the clinical experiences of undergraduate nursing students through the eyes of reflective journals.

\section{METHODOLOGY Design}

This research was the qualitative part of a mixed-method study. Qualitative content analysis was utilized to scrutinize 138 reflective journal entries of undergraduate nursing students to identify their lived experiences in the clinical environment.

\section{Participants and setting}

The participants were 36 undergraduate nursing students in the second and third years of practice from a Public University, School of Nursing, Kenya. The students documented their clinical experiences in a reflective journal during their medicalsurgical clinical attachment at a National Referral Hospital in Kenya between February and August 2018.

\section{Ethical consideration}

The KNH-UoN Ethics and Research Committee granted ethical approval to conduct this study. The National Commission for Science Technology and Innovation (NACOSTI) gave further permission. Each of the participants signed a consent form to participate in this study. To ensure anonymity and confidentiality, the reflection journals were given a code so that no entry could be traced back to a specific undergraduate student.

\section{Instrument}

Data collection was done using a documented account of the student's clinical experiences. Gibb's reflective model [15] guided documentation of reflections. This model consists of six steps description, feelings, evaluation, analysis, conclusion, and action plan. The model was used to enhance the reflections' structuring, thus creating uniformity in how the students documented their clinical experiences [16]. Gibb's reflective model has been established as an effective method as it enables students to benefit from a clinical event by focusing their thoughts [17].

\section{DATA COLLECTION}

Before beginning clinical placements, the purpose and aim of self-reflection were made clear to the students. They were taught how to document their reflection and benefits. The students were issued with coded reflective journals and a sample reflection to guide them since this was a first-time experience. They were to document one write-up per week for four weeks for the second-year cohort and eight weeks for the third-year cohort. The students at the end of the clinical placement, the researcher, picked the reflective journals for analysis.

\section{DATA ANALYSIS}

The journal entries analysis was done through qualitative content analysis. This involved, reading and re-reading and then coming up with familiar words codes for entry in NVIVO version 11 to generate the emerging themes and sub-themes from the undergraduate students' reflections. An independent researcher was allowed to code and develop the ideas to ensure credibility and validity. Later, the issues that arose were compared to the researcher's and refined through consensus that led to the study themes and subthemes. The independent author who participated in the study was skilled and educated in reflective learning as the researcher. Narratives have been used to describe the findings.

\section{RESULTS \\ Participant characteristics}

The participants were 36 undergraduate nursing students in their second and third year of study during a medical-surgical clinical attachment. The students' mean age was $21 \pm 1.34$ years; the majority were female $(61.1 \%)$. The second-year cohort formed a more significant part of the sample, $58 \%$. The journal entries ranged between 2-7 with an average of 4 journal entries per student.

\section{Emerging themes and sub-themes}

Four main themes emerged from the content analysis of 138 journal entries concerning undergraduate nursing students' clinical experiences. The themes include; learning new skills and knowledge, confidence levels, professional practice gaps, and professional support system. 
The second-year nursing students lived experiences were mostly on learning new skills and knowledge, professional practice gaps, professional support system, and confidence levels. Emotional reactions had the lowest representations of lived experiences. On the other hand, the third year had similar themes with a bias towards professional practice gaps more than new knowledge and skills. This paper presents the discussion of the four main themes and the associated themes.

\section{Learning new skills and knowledge}

Common among the second-year students was the theme of learning new skills and experience within the clinical setting. The nursing students expressed that they acquired new skills concerning clinical practice, perfect some of the skills, and master the routines of the clinical environment. One of the journal entry (P28) stated that;

'I had an opportunity to do suctioning, nasogastric tube feeding... I felt an urge for fulfilment and success in achieving what I thought before was complex; the experience and practical doing on real patients is fulfilling.'

In most situations, students gained new knowledge or learned when faced with a new challenge or lacked the expertise to handle a given situation. An accompanied feeling for most students during such circumstances was a feeling of helplessness. In some cases, an experienced nurse mentor's presence helped them overcome the lack of confidence in trying new skills.

Participant journal entry 045 reflected, 'I had an experience of dressing a massive wound... I was initially feeling a lack of confidence, but the presence of an experienced staff who was willing to support helped achieve my objective.'

The third-year cohort gained new knowledge through an encounter with situations that challenged their previous experience and skills. Also, the students gained knowledge through the challenges that they faced in their course of duty. Most notable was recognition among some of them on the need to sharpen their skill and avoid being routine-oriented. They recognized that learning is a continuous process and that classroom instruction is limited in preparing them adequately for the clinical environment

One of the entries (097) stated - 'I did not know tracheostomy interferes with communication. The experience was a challenge for me. I had to go the extra mile to learn. I realized that school does not teach you everything. It's always your interest. Learning something new was satisfying.'

\section{Confidence levels}

All participants regarded the confidence level as a challenge in their clinical environment. Among the students' nurses, there were two categories of nursing students with low confidence levels and assertiveness. The majority of the second-year nursing students were in the former group, and in most cases, they felt helpless to address nurses who engaged in malpractices. However, most of them committed to acting on improving their confidence levels as patient advocates. The student in journal entry 004 expressed

'I observed a patient being bathed inconsiderately with cold water by a senior nurse. I could not confront the nurse. I felt inferior. I will work on my self-confidence so I can be a good patient advocate.

The third-year students expressed their confidence level as being assertive, sometimes 'overconfidence,' and rarely 'lack of confidence' in confronting issues. When faced with a lack of maintenance of nursing care standards, the students demonstrated assertiveness in most cases. For instance, a student journal entry (098) stated;

'A qualified nurse removed from the bedside a new regimen for a patient. I confronted the nurse on the issue, but the nurse was rude. I reported the matter to my clinical mentor, who handled the issue...'

On the other hand, the students demonstrated overconfidence in attempting skills they had not mastered, which led to non-fatal errors, especially in drug administration, as evidenced in the self-reflection by student journal entry 081 .

'I was to prepare ceftriaxone but prepared Cefazolin I did not confirm with the qualified nurse. Just before I went to administer, the nurse asked me what drug I had mixed. I am glad the nurse stopped me before I could commit a drug error...'

\section{Professional practice gaps}

Nearly all the participants were in agreement that they had experienced professional malpractices in one way or another. The focus of the experiences in clinical nursing practice situations was recurrent. Professional practice gaps experienced by the nursing students revolved around non-adherence to nursing standards of practices, poor communication between the nurses and students, mishandling of patients, and nurses verbally abusing each other in the wards. Respondent journal entry 003 expressed;

'Patients are denied privacy during
procedures such as wound dressing, drug
administration, and bed baths...has been a common
situation in the pastfour days'


In expressing their malpractice experiences, it was evident from the reflective journals that most second-year nursing students were "helpless" to face the nurses and correct them.

Respondent entry 002 reflected, 'I noticed that she did not maintain aseptic technique during this procedure that demanded it... I was shocked because I expected a registered nurse to follow what the Nursing Council of Kenya states about aseptic technique. I felt intimidated because she was more experienced than me.'

However, some nursing students were able to face nurses whenever they felt they did something wrong through their preceptors or nurse mentors. Of interest in this was that they confronted them on all other issues except matters of non-adherence to professional standards.

\section{Professional support system}

The professional support system referred to the type of support the participants had or lacked in the clinical setting. Participants frequently used the word 'teamwork' or 'team spirit' to describe the supportive environment in the clinical setting. Among the participants, sources of support in their learning came from role models, nurse preceptors, fellow students, and lecturers themselves. Although the participants' experience with the existing support sources was mostly positive and encouraging, some students had a negative feeling about the nurses' lack of support.

There were mixed feelings concerning role models, with some of the participants expressing that they have good role models amongst the nurses while some felt that they lacked a role model. For example, one student journal entry 046 stated

'A primary nurse was nice to me... This nurse allowed me to do many procedures under her supervision and instruction...I had the best feeling ever in my life".

Encounters with 'bad' role models and sometimes lack of supervision lead to feelings of confusion on what the students ought to do in a given client situation. However, some students stated that lack of support during their placement only motivated them to be more proactive and learn critical thinking skills. For example, one journal entry 029 reported

'I was Feeling confused because of not being given an orientation in a new working environment. Was left to work unsupervised had to rely on another student to know what to do. The qualified nurse left the ward without handing over to me...'
Some of the nurses' willingness to learn from the students created unidirectional mutual support, as stated by Respondent entry 002

'As a student, I was amazed to find registered nurses who could learn from students... correct, teach the students. Wow! is all I can say for the health practitioners in this ward.'

\section{DISCUSSION}

This study's findings indicate that student nurses in Kenya face various enhancers and hurdles to their learning in the clinical environment that affects their ability to achieve their learning objectives. Enhancers of clinical experiences for student nurses include a professional support system, opportunities for learning new knowledge and skills, and self-motivation. Confidence or lack of it is a considerable determinant of self- motivation to engage in performing new skills. The level of confidence is directly related to the length of time of exposure to the clinical environment.The outcomes of the current study are mirrored by another study which eludes that confidence is a key factor in nursing students learning [18]. Educators, therefore, need to evaluate curriculum implementation strategies for undergraduate nursing program to allow adequate time in the clinical area for the development of selfconfidence. Building confidence in undergraduate student nurses plays a role in helping them become effective practitioners [19].

The clinical environment offers an excellent opportunity for learning new skills, as demonstrated in this study. These findings resonate with research done by Chong [9], who found that exposing students to the clinical environment automatically led to acquiring new knowledge and skills. The majority of students' selfconfidence challenged new skills or faced cases of professional malpractice committed by qualified nurses. Jamshidi et al. [11] identified that self-confidence was necessary for building a clinical skills portfolio. However, the lack of a supportive nurse-student relationship hampers its development. Developing countries face a significant challenge of providing adequate supervision due to increased workload for the nurse preceptors [20]. The preceptors may view the student nurses as increased workload ending up neglecting their learning needs. There is, therefore need for student-led self-directed learning strategies so that the learner drives their learning process [18].

The professional support system in the form of good role models enhanced learning in this study [13]. Found that $74 \%$ of student nurses express satisfaction with their clinical learning when they relate well with other nursing staff. Role models influence the students towards deciding on the type of practitioner they want to be or not [21]. Exposure to wrong role models discourages students from nursing work and can be a factor in professional attrition [21]. Students in this 
study experienced similar feelings of discouragement and shock on encountering nurses who did not maintain nursing practice standards or a caring atmosphere [22], on the other hand, found that when student nurses interacted with wrong role models, they were able to form imagery of the type of nurse they want to be in the future. When qualified nurses do not follow standard operating procedures in the patient's care, the student nurses end up frustrated in their desire to learn and struggle to integrate into the profession.

The clinical environment's reality is such that it is unpredictable and can present challenges to novice student nurses. The findings in this study of students facing various unprecedented events like discrimination, tension, and conflicts have been attributed in other studies as factors that impair learning process [11, 14]. Student nurses require an enhancing environment to grow in their professional skills; thus, there is a need to address the identified stressors through a multidisciplinary approach that involves both the academic staff and the clinical educators.

\section{Implications for clinical education}

Student nurses need to be encouraged to document their reflections during clinical practicum to develop their clinical reasoning skills, learn from their experiences, as well as a channel for debriefing. Analysis of student reflections can help improve the clinical learning environment so that the nurse of tomorrow is more prepared to handle patient care situations confidently. The Nursing Council of Kenya, mandated by the government to maintain a high level of nurse training standards, can incorporate reflective writing as part of undergraduate curricula to improve student nurses' clinical skills. The incorporation could also be an indirect way of evaluating the suitability of clinical sites for nurse training. Clinical sites, on the other hand, can develop strategies to respond to the gaps identified in the clinical environment to enhance student learning

\section{LIMITATIONS}

This study occurred in a National Referral hospital whose clinical setting may be characterized by unique student experiences different from the private sector (resource enabled) and county hospital (resourceconstrained). Therefore, generalization to these sites may not be appropriate. This study recommends a future comparative study in different clinical settings.

\section{CONCLUSION}

This study aimed to explore the lived clinical experiences of undergraduate nursing students. From the findings, it is clear that nursing students experience both positive and negative encounters that build their confidence and frustrate their desire to learn, respectively. Addressing the hindrances to student learning is imperative.

\section{ACKNOWLEDGEMENT}

This study acknowledges Teddy Gafna, the statistician, in providing the software for data analysis. Special thanks to the students who participated in this study.

\section{REFERENCES}

1. Gaberson, K., \& Oermann, M. (2010). Clinical teaching strategies in nursing. Springer publishing company.

2. Papastavrou, E., Lambrinou, E., Tsangari, H., Saarikoski, M., \& Leino-Kilpi, H. (2010). Student nurses experience of learning in the clinical environment. Nurse Education in Practice, 10(3), $176-182$.

https://doi.org/10.1016/j.nepr.2009.07.003

3. Silvia, B., Valerio, D., \& Lorenza, G. (2012). The reflective journal: A tool for enhancing experiencebased learning in nursing students in clinical practice. https://doi.org/10.5430/jnep.v3n3p102

4. Bjerkvik, L. K., \& Hilli, Y. (2019). Reflective writing in undergraduate clinical nursing education: A literature review. Nurse Education in Practice, 35, 32-41. https://doi.org/10.1016/j.nepr.2018.11.013

5. Hwang, B., Choi, H., Kim, S., Kim, S., Ko, H., \& Kim, J. (2018). Facilitating student learning with critical reflective journaling in psychiatric mental health nursing clinical education: A qualitative study. Nurse Education Today, 69, 159-164. https://doi.org/10.1016/j.nedt.2018.07.015

6. Chaffey, L. J., Leeuw, E. J. J. de, \& Finnigan, G. A. (2012). Facilitating Students' Reflective Practice in a Medical Course: Literature Review. Education for Health, 25(3), 198. https://doi.org/10.4103/1357-6283.109787

7. Lasater, K., \& Nielsen, A. (2009). The Influence of Concept-Based Learning Activities on Students' Clinical Judgment Development. Journal of Nursing Education, 48(8), 441-446. https://doi.org/10.3928/01484834-20090518-04

8. Karimi, S., Haghani, F., Yamani, N., \& Najafi Kalyani, M. (2017). A Qualitative Inquiry into Nursing Students' Experience of Facilitating Reflection in Clinical Setting [Research Article]. The Scientific World Journal. https://doi.org/10.1155/2017/6293878

9. Chong, M. C. (2009). Is Reflective Practice a Useful Task for Student Nurses? Asian Nursing Research, 3(3), 111-120. https://doi.org/10.1016/S1976-1317(09)60022-0

10. Löfmark, A., \& Wikblad, K. (2001). Facilitating and obstructing factors for development of learning in clinical practice: a student perspective. Journal of advanced nursing, 34(1), 43-50.

11. Jamshidi, N., Molazem, Z., Sharif, F., Torabizadeh, C., \& Najafi Kalyani, M. (2016). The Challenges of Nursing Students in the Clinical Learning Environment: A Qualitative Study [Research 
Article]. The Scientific World Journal. https://doi.org/10.1155/2016/1846178

12. Warne, T., Johansson, U.-B., Papastavrou, E., Tichelaar, E., Tomietto, M., den Bossche, K. V., Moreno, M. F. V., \& Saarikoski, M. (2010). An exploration of the clinical learning experience of nursing students in nine European countries. Nurse Education Today, 30(8), 809-815. https://doi.org/10.1016/j.nedt.2010.03.003

13. Lawal, J., Weaver, S., Bryan, V. D., \& Lindo, J. L. M. (2015). Factors that influence the clinical learning experience of nursing students at a Caribbean school of nursing. https://doi.org/10.5430/jnep.v6n4p32

14. Msiska, G., Smith, P., \& Fawcett, T. (2014). The "lifeworld" of Malawian undergraduate student nurses: The challenge of learning in resource poor clinical settings. International Journal of Africa Nursing Sciences, 1, 35-42. https://doi.org/10.1016/j.ijans.2014.06.003

15. GIBBS, G. (1988). Learning by Doing: A Guide to Teaching and Learning Methods. Further Education Unit. https://ci.nii.ac.jp/naid/10013454789/

16. Husebø, S. E., O’Regan, S., \& Nestel, D. (2015). Reflective Practice and Its Role in Simulation. Clinical Simulation in Nursing, 11(8), 368-375. https://doi.org/10.1016/j.ecns.2015.04.005

17. Watkins, C., Hart, P. L., \& Mareno, N. (2016). The effect of preceptor role effectiveness on newly licensed registered nurses' perceived psychological empowerment and professional autonomy. Nurse Education in Practice, 17. https://doi.org/10.1016/j.nepr.2016.02.003

18. Panduragan, S. L., Abdullah, N., Hassan, H., \& Mat, S. (2011). Level of Confidence among Nursing Students in the Clinical Setting. Procedia Social and Behavioral Sciences, 18, 404-407. https://doi.org/10.1016/j.sbspro.2011.05.059

19. Porter, J., Morphet, J., Missen, K., \& Raymond, A. (2013). Preparation for high-acuity clinical placement: Confidence levels of final-year nursing students. Advances in Medical Education and Practice, 4, 83-89. https://doi.org/10.2147/AMEP.S42157

20. Gemuhay, H. M., Kalolo, A., Mirisho, R., Chipwaza, B., \& Nyangena, E. (2019). Factors Affecting Performance in Clinical Practice among Preservice Diploma Nursing Students in Northern Tanzania. Nursing Research and Practice, 2019, 3453085. https://doi.org/10.1155/2019/3453085

21. Jack, K., Hamshire, C., \& Chambers, A. (2017). The influence of role models in undergraduate nurse education. Journal of Clinical Nursing, 26(23-24), 4707-4715. https://doi.org/10.1111/jocn.13822

22. Grealish, L., \& Ranse, K. (2009). An exploratory study of first year nursing students' learning in the clinical workplace. Contemporary Nurse, 33, 8092. https://doi.org/10.5172/conu.33.1.80. 